\title{
An In-Depth Examination of Reasons for Autopsy Acceptance and Refusal in Northern Tanzania
}

\author{
Lauren S. Blum, ${ }^{1 \star}$ Francis P. Karia, ${ }^{2,3}$ Elizabeth F. Msoka, ${ }^{3}$ Martha Oshosen Mwanga, ${ }^{3}$ John A. Crump, ${ }^{4,5,6}$ \\ and Matthew P. Rubach ${ }^{4,5}$ \\ ${ }^{1}$ Duke University, Durham, North Carolina; ${ }^{2}$ Kilimanjaro Christian Medical University College, Moshi, Tanzania; ${ }^{3}$ Kilimanjaro Christian Medical \\ Centre, Moshi, Tanzania; ${ }^{4}$ Division of Infectious Diseases and International Health, Department of Medicine, Duke University Medical \\ Center, Durham, North Carolina; ${ }^{5}$ Duke Global Health Institute, Duke University, Durham, North Carolina; ${ }^{6}$ Centre for International Health, \\ University of Otago, Dunedin, New Zealand
}

\begin{abstract}
Uncertainty about the causes of death (COD) in low- and middle-income countries (LMICs) has been recognized as a constraint to global health and development. Although complete diagnostic autopsy (CDA) is the best way to assess COD, it is uncommon in LMICs because of low investment priority and assumptions about poor acceptability. Social science research was conducted from May 2016 through July 2017 to examine issues related to acceptability of CDAs in northern Tanzania where autopsy was being offered in two referral hospitals to assess COD associated with febrile illness. Initial formative research entailed 29 key informant interviews, seven observations of burial practices, and four group discussions. In-depth interviews were conducted with families of deceased, including nine families that accepted and 11 families that refused CDA. The formative research identified concepts related to death, understandings of CDA, and cultural practices and psychosocial considerations associated with death that informed the authorization process. Most families who accepted CDA cited the desire to get clarity regarding the COD as a primary reason for acceptance. An unexpected finding was that CDA is perceived as a means to determine witchcraft involvement, a common explanation for COD and a common reason for postmortem acceptance. Death resulting from chronic illness or conditions presumed to have a clinical diagnosis were reasons for CDA to be viewed as unnecessary. The timing, way families were approached, and content of information shared during authorization influenced acceptance and refusal of CDA. Findings show that CDAs can be acceptable in settings where traditional disease models prevail.
\end{abstract}

\section{INTRODUCTION}

Uncertainty about the contribution of specific causes of death (COD) in low- and middle-income countries (LMICs) has been recognized as a constraint to global health and development. ${ }^{1,2}$ Complete diagnostic autopsy (CDA) is considered the gold standard to determine death etiology, superior to both clinical diagnosis and verbal autopsy. ${ }^{2-5}$ While CDA procedures have had a fundamental role in increasing scientific knowledge, in recent decades, there has been a sharp decline in clinical postmortem procedures. ${ }^{6}$ Though CDAs might be most valuable in LMIC health systems, clinical CDA is particularly uncommon in LMICs because of low investment priority and assumptions about poor acceptability. ${ }^{2}$ Biomedical researchers frequently claim that authorization for CDAs would be low in resource-poor settings because of apprehensions guided by cultural belief systems and religious principles and concerns about the disfiguring nature of CDA procedures. ${ }^{1,3}$ It is presumed that autopsy would be less accepted among Muslims because of religious tenets opposing altering the dead body, removing organs, and delaying the burial. ${ }^{7,8}$ Despite these perceived barriers, CDAs are mandated in many LMICs in the context of police investigations of homicides, suicides, unintentional injuries, or other unnatural deaths.

Few studies have been conducted in LMICs to understand perceptions of CDA, barriers and facilitators to acceptance, and acceptance levels. Research examining attitudes toward autopsy in Nigeria found fears of mutilation of the body and funeral delay were among the most common explanations for refusal. ${ }^{9}$ In Zambia and Uganda, where the proportion of families accepting CDA was $25 \%$ and $38 \%$, respectively, reasons for refusal included that knowledge of the cause of death was no longer useful, death certificate was already

*Address correspondence to Lauren S. Blum, Tulane University, 2211 Arden Rd., Baltimore, MD 21201. E-mail: laurensblum@yahoo.com. issued, transport of the body had been arranged, desire to avoid delays in the burial, and satisfaction with the clinical diagnosis. ${ }^{10,11}$ Notably, religious and cultural practices were rarely mentioned. These studies, which used closed-ended, structured guides, did not provide reasons for CDA acceptance nor information on the authorization process.

We conducted a qualitative study on the social acceptability of autopsy in the Kilimanjaro Region, Tanzania. Formative research was initially carried out to assess views on death, perceptions of $\mathrm{CDA}$, and ways to approach families of recently deceased hospital patients among people from a range of cultural, religious, and socioeconomic backgrounds, with a main goal to inform the CDA authorization process. The study also explored actual reasons for acceptance and refusal of CDA by families of decedents who had recently died in hospital settings. The combination of approaches was designed to facilitate an assessment of the information gathered during the hypothetical formative phase compared with information gathered from families confronted with real decisions about autopsy acceptance. Our study was part of research being carried out to determine the etiology of fatal febrile illness in northern Tanzania where previous febrile illness studies reported that $60 \%$ adult and $67 \%$ of pediatric in-hospital deaths had no laboratory-confirmed diagnosis. ${ }^{12,13}$

\section{RESEARCH METHODS}

Study setting and population. Qualitative research was carried out from May 2016 through July 2017 in the Moshi Municipal, Moshi Rural, and Hai districts of the Kilimanjaro Region of northern Tanzania. The area is comprised of both flat lands and mountainous terrain, with agriculture, livestock raising, and commerce being the primary occupations of inhabitants. ${ }^{14}$ Although the main ethnic groups are Chagga, Pare, and Wakahe, the population is composed of people from a range of ethnic backgrounds, each with their own traditions and belief systems. Residents living in the research districts report affiliation with 
Christianity (81\%) and Islam (16\%). ${ }^{15}$ Islam appeared in coastal East Africa centuries before Christianity, with the expansion of trade in the 19th century spreading Islam to the interior of Tanzania. ${ }^{16-18}$ Christianity was introduced in the Kilimanjaro Region by German and British missionaries in the 19th century. ${ }^{18,19}$ Before colonization, indigenous religions guided by locally defined values, customs, and identities are reported to be widely practiced throughout Tanzania. ${ }^{16,20,21}$ Traditional religions frequently venerated a hierarchy of spiritual beings appeased through sacrifices. $^{20}$ Certain community members are reported to have possessed with capabilities to communicate with spiritual powers, whereas others held mystical powers referred to as witchcraft or sorcery to inflict misfortune or even death. ${ }^{20}$ At present, localities in Tanzania are characterized by religious pluralism, intertwining longstanding indigenous religious and cultural traditions and beliefs with more modern religious doctrine and ideology. ${ }^{20,22}$

The health system in the Kilimanjaro Region includes government and private facilities offering biomedical care, allopathic practitioners selling medicines, and a range of magico-religious healers. ${ }^{23}$ The government health system offers biomedical care from the tertiary to community level, with private health facilities also available in urban and peri-urban communities. Modern medicines are sold in pharmacies with and without prescriptions and by drug retailers in shops. Prayer constitutes an important approach used by Christians and Muslims to manage illness, although magicoreligious paradigms invoking deities or ancestral spirits and involving sacrifice or concoctions to treat illness are also practiced. Indigenous healers include herbalists who use curative remedies made of traditional herbs and people possessing magical and witchcraft powers (sorcerers or witch doctors) believed capable of treating health conditions caused by evil forces or inflicting harm, bad luck, ill-health, or even death to address jealousy or conflict.

Moshi, the Kilimanjaro regional capital, is the home of several hospitals where both rural and urban dwellers obtain care, particularly for more serious health conditions. The study was conducted in the Kilimanjaro Christian Medical Centre, the referral hospital for Tanzania's northern zone, and Mawenzi Regional Referral Hospital, a regional hospital for Kilimanjaro. Both hospitals are offering CDAs and minimally invasive tissue sampling (MITS) as part of research to assess the cause of febrile illness and death, with CDAs offered first and MITS offered to those declining CDA. Before the research, community advisory board members and religious and political leaders living in the research area were informed that CDA and MITS procedures would be offered free of charge in the two study hospital settings. No additional community engagement or outreach activities related to the autopsy procedures were conducted.

Study design, sampling, and methods of measurement. We used a mix of open-ended and semi-structured methods including key informant interviews, observations, and group discussions during the formative phase. In-depth interviews were used during the second phase of the research. Data collected during the formative phase were used to inform the autopsy authorization process to be carried out with family members of deceased patients approached for autopsy procedures, as well as the content of in-depth interviews conducted with families of deceased patients who had either accepted or refused autopsy procedures.

Formative research. Key informants were selected purposively and included respondents who could potentially provide insights into barriers and facilitators to autopsy acceptance. Main topics focused on community perceptions of disease causality and age at death, attitudes toward treatment of the body postmortem, perceptions related to postmortem examinations conducted in hospital settings, and considerations regarding obtaining authorization for postmortem procedures. Informants included clinicians working on the pediatric or internal medicine wards in the two hospital settings, religious leaders representing the three major religious denominations in the area, medical administrators, government officials, and traditional leaders in urban and rural communities. The target was to continue identifying new informants until no new information emerged.

Observations of family members of recently deceased hospital patients were conducted to understand the period immediately after the death, including roles and reactions of family members, care of the dead body, and burial rituals and practices that could potentially influence autopsy acceptance. Convenience sampling was used to identify family members of recently deceased patients on the internal medicine and pediatric hospital wards of the study hospitals.

Focus group discussions were administered with groups of community members living in urban Moshi or rural settings, with the target of conducting four discussions. The purpose was to collect information on local causal explanations for death, understandings of autopsy procedures, family decision-making postmortem, and how best to communicate with families about autopsy procedures. In the urban setting, we purposively held one discussion with residents living in a lowincome congested area, comprised of small households sharing water sources and latrines, whereas a second discussion was conducted in a middle-income neighborhood housing multiple bedroom homes with internal plumbing and spacious compounds. We requested community leaders to identify communicative and respected men and women to participate.

Family members approached for CDA approval. In-depth interviews were conducted with family members of patients who had suffered from a presumed infectious illness and had died on the pediatric or internal medicine wards of the hospitals offering autopsy. Family members were to be approached shortly after and up to 24 hours after the death by clinicians trained to carry out autopsy authorization. The clinicians were required to provide family members of deceased information on the purpose of the research, the autopsy procedures being offered, benefits and risks associated with the procedures, costs involved, and confidentiality. Clinicians stipulated a final autopsy report would be available within 60 days of the autopsy procedure consistent with the College of American Pathologists guidelines. The goal of the in-depth interviews was to assess the perceived cause of death, understandings of postmortem procedures, perceptions of the authorization process, and why families accepted or refused postmortem procedures. Eligible families from both hospitals were identified after patients died, with the target to include a total of 20 instances of acceptance and refusal.

Data collection. Data collection was carried out by two female and one male Tanzanian qualitative researchers, with one also acting as a supervisor. All of the researchers had a university degree, and two held Master's degrees. Using a guide to address study topics, initial data collection involved key informant interviews. Interviews were designed to last approximately 1 hour 30 minutes.

Observations started in the hospital and continued up to the burial. Shortly after the death, nurses summoned the researchers to the ward and introduced them to family members of the deceased. Researchers observed initial family responses to the death, preparations of the body for burial, religious and cultural ceremonies, 
and the burial. When attending burial ceremonies, researchers were careful to adhere to religious and cultural norms. Because of the solemn nature of the event and out of respect for family members, researchers recorded observations only after leaving the ceremony. Researchers used a guide to record information in a narrative form. Observations of the religious ceremonies and burial generally took an entire day.

Group discussions comprised people with similar background characteristics and held in a relatively private space such as a family compound or community meeting area, with sessions limited to 1 hour 30 minutes. A moderator led discussions, and another researcher took notes to facilitate data transcription. A guide reflecting study themes and preliminary results procured through other data collection methods was used.

A family member of deceased patients who accepted or refused autopsy was either approached in the hospital, or if the family had already left the hospital, by telephone to identify a convenient time to schedule an in-depth interview. The person contacted was the family member named on the form documenting the autopsy authorization encounter. Interviews were carried out 3-10 days after the death either in a private location in the hospital such as a medical office, the home of the family of the deceased, or if requested by the respondent, a car. Interviews were limited to 45-minute duration.

Key informant, in-depth interviews, and group discussions were administered in Kiswahili, the national language of Tanzania and the first language spoken by most Kilimanjaro residents. Interviews and group discussions were audiorecorded; interviewers also took handwritten notes that provided additional insights into the data.

Data analysis. Audio-recorded interviews were transcribed in Microsoft Word (Microsoft, Redmond, WA). An iterative process involving the review of completed interview transcripts and additional questioning continued until data saturation was reached. Separate coding systems were developed for key informant interviews, in-depth interviews, and group discussions. Coding categories were derived from initial research themes and questions and key concepts that emerged during data collection. A codebook with detailed definitions was developed with input from all of the researchers. Coding of key informant interview transcripts was performed by two researchers and the study supervisor on ATLAS.ti (ATLAS.ti Scientific Software Development $\mathrm{GmbH}$, Berlin, Germany), a text-organizing software, whereas in-depth interview, focus group discussion, and observation transcripts were coded in matrixes. ${ }^{24}$ Content analysis was used to identify trends of concepts in and across individual codes. The combination of data and methodological triangulation facilitated data analysis across research methods (key informant interviews, in-depth interviews, observations, and group discussions) and across and between respondents.

Research ethics. The study protocol was reviewed and ethical approval granted by the Kilimanjaro Christian Medical Centre Research Ethics Committee, Moshi, Tanzania; the Tanzania National Institute for Medical Research National Research Ethics Coordinating Committee, Dar es Salaam, Tanzania; and the Duke University Health System Institutional Review Board, Durham, North Carolina, United States. Signed informed consent was obtained from all the key informants and in-depth interview respondents, focus group participants, and families observed before data collection.

\section{RESULTS}

Formative research to identify potential facilitators and barriers to postmortem. Descripton of respondents. Key informant interviews were conducted with religious leaders (6), healthcare providers (12), local government officials (3), medical administrators (4), and village or street leaders (4) (Table 1). Religious leaders were Catholic, Protestant, and Muslim. Health providers included medical doctors and nurses. Government officials and community leaders represented urban and rural areas. Seven observations were carried out with family members of five adults and two neonates recently deceased on a hospital ward. Four group discussions comprised of adult men and women representing prominent religious and ethnic affiliations in the region were conducted in two rural villages and two urban settings.

Causal explanations of death. Key informants and group discussion participants reported that people's explanations for death related to biomedical illness; accidents linked to excessive alcohol consumption, misuse of herbal medicines, and road accidents; suicide, homicide, and other unnatural deaths requiring police investigation; and witchcraft, sacrifices, supernatural causes, or "suspicious," or unclear deaths. Some group discussion participants also mentioned lack of rapid treatment or negligence by healthcare providers. Group discussion participants claimed that witchcraft is often assumed when hospital care does not reverse a condition or a medical diagnosis is not available. Medical professionals admitted that they frequently do not share the probable biomedical cause of death.

Key informants and group participants indicated that God's will is a common explanation for chronic illness resulting in death, as well as elderly or young infant deaths. Disease evoking shame such as HIV/AIDS or tuberculosis is attributed to punishment from God. Key informants claimed that people showing disrespect to God or failing to subscribe to religious doctrine may fall victim to a supernatural curse. Death explained by predestination is common according to focus group participants group participants, particularly among Muslims who believe the timing of death is predetermined.

TABLE 1

Research respondents according to data collection methods, qualitative autopsy acceptability study, northern Tanzania, 2016-2017

\begin{tabular}{lr}
\hline \multicolumn{1}{c}{$\begin{array}{c}\text { Research methods and } \\
\text { types of respondents }\end{array}$} & $\begin{array}{r}\text { Total, } \\
N\end{array}$ \\
\hline Phase 1: Formative research & \\
Key informants & 12 \\
Health providers including medical doctors and nurses & 6 \\
Religious leaders of Catholic, Lutheran, and Muslim faith & 6 \\
Medical administrators at the regional and district level & 4 \\
Local government officials representing rural and urban & 3 \\
populations & \\
Village or street rural or urban leaders & 4 \\
Observations & 7 \\
Focus group discussions (seven to nine participants per group) & 2 \\
Men and women living in a rural village & 1 \\
Men and women living in a middle-income urban setting & 1 \\
Men and women living in a low-income urban setting & \\
Phase 2: Families approached for postmortem & \\
In-depth interviews & 11 \\
Family members who accepted postmortem & \\
Family members who refused postmortem & \\
\hline
\end{tabular}


Desire to learn the cause of death. All types of respondents proposed that sudden death of people with no prior illness history is more likely to foment interest in learning the cause. Death in younger, productive family members is difficult to accept, invoking questions. Focus group participants also mentioned that suspected hospital worker negligence may encourage people to seek explanations to apportion blame and for personal reassurance. Respondents concurred that alleged homicide or suicide would encourage people to learn the cause.

Key informants and group discussion participants agreed there would be less interest in the cause of death resulting from illnesses that are chronic, convey stigma, occur in elderly populations locally defined as more than 60 years, or among neonates, or attributed to God's plan. A village leader said,

A disease like HIV, family members do not talk about it openly. Interest in learning the cause also depends if the deceased suffered a long time, then they won't ask many questions. But if the death occurred within a short time, they will question what happened, what caused the death.

Respondents presumed the cause to be already known in chronic illness cases. Death in older people is considered part of the life cycle and expected, whereas young infants are not viewed as fully human, and thus, death is not questioned. Some key informants mentioned that poor people may avoid learning the cause because of fear of being blamed for failing to take appropriate medical action.

There was ambiguity about suspected witchcraft. Some key informants and focus group participants speculating that suspected witchcraft may lead to refusal, whereas others predicted that people may want to determine a scientific explanation to allay witchcraft suspicions.

Perceptions and acceptance of autopsy. Key informants stressed that people are poorly informed about CDA, which is locally called and will henceforth be referred to as postmortem. Across group discussions, there was consensus that postmortem is associated with police investigations involving sudden and controversial death related to homicide, suicide, and accidents. A focus group participant in the low-income urban area said,

The community knows only one type of postmortem that is done when there is homicide or suicide and other strange deaths. It is different when it comes to the postmortem of someone in the hospital after being ill, our community will not understand that, they will think there is something else, that you want organs or to double your wealth by bringing a human organ to the local healer.

Focus group participants generally understood that postmortem involves opening the body to assess the cause of death. Some questioned whether the investigation occurs on a dead or living body.

Proposed determinants of acceptance generally coincided with factors that may trigger the desire to learn the cause of death. Key informants and group discussion participants projected that better educated people and those living in urban areas may understand the benefits to family members and science and be more willing to accept postmortem. Commonly speculated reasons for refusal included apprehensions about harming, disfiguring, or causing pain to the body, with group discussion participants explaining that Muslims believe the body feels pain up to the burial. Respondents also raised concerns that bleeding or oozing wounds may interfere with ritual washing or delay the burial, particularly among Muslims who adhere to strict precepts that the body remains pure and intact and the burial adhere to time restrictions. Some focus group participants suggested that people may feel that death has occurred and nothing can be accomplished through postmortem. Death linked to disease associated with stigma, particularly HIV/AIDS, was anticipated to lead families to decline postmortem.

Preexisting beliefs anticipated to adversely affect acceptance included that organs and body parts will be removed and used for transplant (e.g., kidneys, sexual organs to enhance sexual prowess), witchcraft, or traditional rituals with some specifying to increase wealth, to aid in the training of medical students, or for the fabrication of medicines or medical supplies.

There was agreement that community education about postmortem and its scientific benefits will allow people to make informed decisions and increase acceptance when families are approached in hospitals.

Obtaining authorization. Key informants and group participants anticipated that information provided during authorization will be essential to postmortem acceptance, highlighting the need to convey the purpose, a description of the procedure, and benefits. Notifying family members that clinical misdiagnosis is frequent and that knowledge gained will be used to improve disease prevention and treatment was considered paramount to acceptance. Key informants recommended authorization be carried out in person and in a private location and be held after the family has had time to grieve, with many underscoring that Muslims will only accept if contact is made shortly after the death. Observational data showed that immediately after death when families experience the initial shock can be chaotic, with women frequently wailing. Other recommendations included showing sympathy and respect toward the family, avoiding information that may raise fears, using simple, understandable language, dispelling negative beliefs about the procedures, and being willing to respond to questions. Key informants and group discussion participants suggested that trust would be enhanced if the clinician who had treated the deceased is present. Offering the postmortem procedure and embalmment for free was considered appropriate, although key informants indicated that covering other expenditures such as for the coffin or transport of the body to the burial site may raise concerns about coercion. Informing families that the cause of death will appear on the death certificate, which in some cases can facilitate statutory benefits such as retirement pension, social security funds, educational loans, and inheritance of assets, and providing a report with a definitive explanation of the cause were anticipated to be motivators to acceptance.

Actual barriers and facilitators identified by families of deceased approached for postmortem. Acceptance. Nine families who accepted autopsy were interviewed. Most of the deceased were 1-60 years old, Catholic, and from rural areas (Table 2). Eight decedents had been suffering from a serious health condition for several months with one HIV-infected. However, four families referred to the death as sudden.

All respondents described postmortem as a procedure to assess the cause of death with some suggesting it provides a means to determine whether the etiology is human-inflicted or disease-related. One family respondent (P5) said, 
TABLE 2

Social and economic background information of deceased whose family members did or did not accept postmortem procedures, qualitative autopsy acceptability study, northern Tanzania, 2016-2017

\begin{tabular}{lcc}
\hline \multicolumn{1}{c}{ Variable } & $\begin{array}{c}\text { Deceased whose family } \\
\text { accepted postmortem }(N=9)\end{array}$ & $\begin{array}{c}\text { Deceased whose family } \\
\text { refused postmortem }(N=11)\end{array}$ \\
\hline Age & 1 & 2 \\
$0-11$ months & 2 & 1 \\
1-17 years & 5 & 4 \\
18-60 years & 1 & 4 \\
$\quad$ 60 years & & \\
Religion & 7 & 5 \\
$\quad$ Catholic & 1 & 5 \\
$\quad$ Lutheran & 1 & 1 \\
$\quad$ Muslim & & 3 \\
Home setting & 4 & 8 \\
$\quad$ Urban & 5 & 5 \\
$\quad$ Rural & & 6 \\
Gender of deceased & 5 & \\
$\quad$ Male & 4 & \\
Female & & \\
\hline
\end{tabular}

What I know is it is done to the dead bodies to confirm if the death has been caused by someone or if it is an illness, but also after being educated (though the authorization process) I have learned there are doctors who want to know more about existing diseases. All this can be learned through postmortem.

None had had previous firsthand experience with postmortem, although one family respondent considered biopsies performed on the living patient comparable. Another respondent used postmortem procedures on his cattle to diagnose disease.

Seven families were approached by the clinical team seeking postmortem authorization the morning after the death. The other two, including the only Muslim family, were requested authorization a few hours after the death. Seven families were approached while in the hospital. The other two were originally contacted by telephone, but a family member returned to the hospital to talk with the team seeking authorization. All respondents viewed the timing of the initial contact appropriate. Postmortem authorization was administered in a private area, either in the morgue, an office, or a consultation room in the hospital. Respondents reported that clinicians obtaining postmortem authorization indicated that they were part of a study team examining febrile illness, that they were requesting postmortem to determine the cause of death, and that the information obtained would enhance disease treatment and prevention and could be beneficial to relatives, community members, and broader Tanzanian society. The clinical team explained the procedure, costs covered, and that a report would be provided. Clinical officers obtaining consent were described as sympathetic, transparent, and knowledgeable about the procedures, providing a good description and assuring family members they would learn the cause of death.

All family respondents reported accepting postmortem to learn the cause of death. Family members provided multiple explanations for acceptance (Table 3). The most common primary reason related to ambiguity about the biomedical diagnosis and treatment, with families frequently reporting receiving different diagnoses from different health providers. A family member (P9) of a 15-year-old decedent said,

The benefit of postmortem is to know the cause of death of the deceased, we just wanted to know the exact reason because people die for various reasons. The child wasn't sick, his death was sudden, he was bleeding, we were worried as to why he was bleeding, this is what moved us to go for postmortem.

Other explanations related to enhancing scientific knowledge, investigating death that was sudden and raised suspicion, and determining whether witchcraft was involved. This respondent (P2) said,

Despite all of the tests that were done, when my family member died in the hospital we were not given answers as to what kind of disease killed her. After death, we were asked to give permission for postmortem. We were told that the benefits are not only for us but for future generations. Maybe our relative had an unknown disease and they would be able to find out what disease killed her through postmortem. I thought it important to allow the doctors to conduct postmortem because it is beneficial to the community and world at large.

Deaths potentially associated with witchcraft more often occurred in people who had been living outside Moshi, presented with unusual and sudden symptoms such as convulsions or bleeding from the orifices, were in a conflict related to money, or were associated with people perceived to be afflicted by evil spirits. One case study, involving adult children accusing their stepmother of killing their father through witchcraft, is presented in Box 1. One of the respondents (P7) stated,

If the results come up negative (for biomedical causes) it means there is no disease that caused the death, this will show us the real cause. . . Father was not suffering from anything and there was something found on his bed wrapped up in a plastic bag. From there onward he became ill. After 2 to 4 days he started to be sick, his legs and arms were painful and swollen. After a

Box 1

Case study of suspected witchcraft

\footnotetext{
- Patriarch with three wives living in rural Moshi

- Dispute over inheritance, causing conflict between the first and second wives

- Husband died suddenly; before death, unable to walk and talk, had convulsions

- Children of the first wife believed the second wife used witchcraft to kill father

- Waiting for postmortem report to determine witchcraft involvement

- If no disease identified, conclusion will be the stepmother responsible for death
} 
TABLE 3

Primary and secondary reasons that families of deceased accepted postmortem procedures, qualitative autopsy acceptability study, northern Tanzania, 2016-2017

Reasons for postmortem acceptance

Primary Reasons

- Learn the cause of death

Ambiguity about the biomedical disease and treatment

- Doctors did not share the cause of death

- Need to know if suffered from same disease experienced previously

- If medical diagnosis had been correct, the patient would have recovered

- Received varying diagnoses from different hospitals where treated

- Received effective treatment previously for similar condition

- Hospital stay too short to make a diagnosis

- Another disease may be involved

- Determine if witchcraft was involved

Death occurred suddenly, raising suspicions

Beating or poisoning suspected

- Medical benefits

Strengthen treatment and prevention practices for those living

Enhance identification and treatment of diseases that may affect family members

Secondary reasons

- Postmortem procedure, morgue, and embalmment costs covered

- Team obtaining authorization are trusted, provide confidence

- Team obtaining authorization explained the procedures clearly and had a good approach

- Report on the cause of death will be provided

- Deceased is already dead, good to help those who are living

- Hospital is reputable

- Family members are medical people; knowledgeable, and confident about the procedures

- Use same procedure to identify disease and treat cattle

while he became severely sick. When we went to X hospital he was diagnosed with hypertension and diabetes. We brought him to another hospital and they said he had none of the illnesses diagnosed in the first hospital. . .

Frequent secondary reasons for acceptance included that postmortem and morgue costs would be paid for and the description of the procedure was clear and the team seeking authorization elicited trust.

One-third of families were unable to cite disadvantages to postmortem. Those identifying disadvantages commonly mentioned that it takes a long time to generate the full postmortem report, certain family members believe organs were removed, and conflict about payment ensued with morgue attendants. One respondent (P5) said,

On the other hand, there is organ business. . Witchcraft that involves cutting a toe, a palm of a hand, the heart, or tongue. Such organs are believed to be taken to the witch doctor so that people can get wealth or money, there are so many issues around that. In our case, relatives could have refused because they might think I wanted some of grandmother's organs for witchcraft purposes.

Another respondent (P2) said,

Many people think during postmortem they take out the heart, liver, and kidney and they use them for teaching aids.

Most family respondents recommended sharing information at the community level to improve understandings of postmortem and acceptance.

Refusals. Interviews were administered to 11 families who refused postmortem (Table 2). Most decedents were aged 18-60 years or more than 60 years, Catholic or Lutheran, and from rural areas. All nine deceased adults had been suffering from chronic conditions requiring ongoing medical care, three of whom were HIV-infected. Both infants died suddenly.

All respondents reported that postmortem is performed to determine the cause of death, with several specifying that the procedure is appropriate when the cause is unclear, wrongdoing such as poisoning or another form of murder is suspected, or the death is sudden. Several respondents indicated that the body will be cut and feel pain, organs will be removed, or the procedure is performed for medical training, or to protect clinicians of liability. Few mentioned that findings can be used to advance scientific knowledge. Three respondents, one of whom had a medical background, had either observed a body that had undergone postmortem or witnessed the procedure, with all expressing alarm.

Three families reported that hospital staff originally introduced postmortem procedures when the decedent was alive on the ward, raising questions about the medical care. After the death, six families were contacted by telephone a day later. These respondents reported that postmortem was requested to determine the cause of death, with little additional information provided. Four of the other five families were approached in a hospital ward or corridor shortly after the death when the family was grieving. Two families stated that a description of procedures, scientific benefits, and the fact it was free were clear and the approach and way information was relayed were good. Two other families approached were unable to remember the information presented, stating they were still in shock. Information on the authorization process was not obtained from the last family.

Explanations for refusal are presented in Table 4. Most families gave multiple reasons with the most frequent being that the cause of death had already been diagnosed or was assumed to be known. A family member (P10) said, 
TABLE 4

Primary and secondary reasons that families of deceased refused postmortem procedures, qualitative autopsy acceptability study, northern Tanzania, 2016-2017

Reasons for postmortem refusal Total $\mathrm{N}$

Primary Reasons

- Had received a diagnosis or family assumed the cause of death was already determined Deceased had been diagnosed with HIV-AIDS, leukemia, or a heart defect Deceased had been hospitalized for a long time, assumed cause was known

- Did not get adequate information from the team obtaining postmortem consent

- Approached too early or too late after the death

- Family was preparing for the funeral, did not wat to change arrangements

Family was still very emotional, not able to focus on information provided

- Do not want to cut or disfigure the body

- Stigma associated with HIV/AIDS

Secondary reasons

- Postmortem procedures are done to train doctors

- Family members would suspect organs removed

- Dissatisfied with the medical treatment while the deceased was still alive

- Not a police case; murder, or wrongdoing not suspected

- Did not like being contacted by telephone

- Postmortem procedures cannot reverse the death

- Not necessary to disturb the dead body

- Twin brother of the deceased would experience pain during procedure

was approached it was kind of strange to me. I knew my uncle was admitted for more than a month and assumed doctors already knew the cause. So I asked why they approached me, what did they want to find. . . What I know is postmortem is done for sudden death or poison deaths or corpses found with injuries. Not for a patient who was admitted to the hospital for a month and some days.

A father-respondent (P19) explained,

The X-ray results found a problem with the child's heart and also pneumonia, that is when we did not see the reason to investigate further about the cause of death. So we decided not to accept postmortem.

This father indicated that if the radiograph had not confirmed the cause of death, he may have opted for postmortem to rule out witchcraft and to rule out that his son was sacrificed so that the father could become wealthy. Inadequate information on how families were selected or the procedure was the second most frequent reason for refusal. A family member (P11) said,

People need information about postmortem because it's not easy to understand its benefit or meaning, you need to be well informed. Someone cannot be well informed through the phone... I was shocked in the first place, I asked myself why did they ask me for authorization, what are they thinking about his death? What was the reason when there was no doubt about the cause of death?

Timing, another common explanation for refusal, included being approached too late when funeral arrangements had already been made or too early when the family was highly emotional and some members had not been informed about the death. Family respondent (P16) said,

It is a time when you're in grief, coming to ask about postmortem when the family is still mourning is not appropriate. This is when the relatives of the deceased need consolation.

Two of these families suspected hospital negligence contributed to the death, adding to their distress and reason to decline postmortem. Respondent (P10) said,

Doctors must understand that when a relative is brought to the hospital, it's not that they are happy, it's because they are sick and need help. But when we ask for help and doctors instead are doing other things (chatting on the phone), we feel ignored. After the death, the same doctor comes to us asking for further investigation. We felt they wanted the patient to die to learn from the postmortem. People don't agree to the procedure because sometimes they don't see an effort made by the doctor to save the life of the patient.

Fewer respondents mentioned that they did not want the body cut or disfigured, with one family indicating it would inflict pain on the dead body. In one of these instances, the young parents of an infant were convinced witchcraft had been inflicted by a 'bad' neighbor who had frequent contact with the infant before the death. Both parents opted for postmortem, with the infant's father (P12) stating,

If postmortem is done and they find nothing (biomedical) has caused the death, we would believe the cause was due to witchcraft.

The infant's grandparents opposed "disturbing" the body, overruling the decision of the infant's parents. Stigma associated with HIV/AIDS was mentioned as a primary reason for refusal by one of three family members of an HIV-infected patient.

Common secondary explanations for refusal included concerns regarding the procedure was being conducted for teaching purposes (4), assumptions that organs and body parts would be removed and used to make medicine or for transplant or witchcraft (4), dissatisfaction with the medical 
care when the patient was alive (4), and because murder or violence was not involved, confusion about why the family was approached (3). One family member (P10) stated,

Things such as stitches (believed to be made from muscles) are in the body. Other things are removed for the sake of teaching. When postmortem is done only medical personnel are present, the family receives reports about the findings but no one witnesses the procedure. Later when you come to collect the body, you don't know if the organs were returned or not.

\section{Another respondent (P18) explained,}

They called my sister to ask her if she can give permission for postmortem, but my sister didn't understand the meaning of postmortem because she is from a rural area. Then people around her who attended the burial ceremony started telling her what is done during postmortem, they told her they cut the body, cut the head, and take the brain to manufacture medicines. Some said they want to do it for a teaching practicum for medical students.

Family respondents contended that community-based awareness raising, particularly related to the scientific benefits, would equip people with the knowledge needed to accept postmortem procedures.

\section{DISCUSSION}

To our knowledge, ours is the only study in Africa combining exploratory research and knowledge and views of family members approached for a CDA examination. Perceptions regarding whether there was or was not clarity related to the medical etiology of death influenced both acceptance and refusal. A surprising finding is that a biomedical diagnostic procedure such as postmortem was perceived as a means to determine a role for witchcraft, a common causal explanation for death, and a common reason for postmortem acceptance. The research identified factors to consider related to the timing, means of contact, and content for a culturally appropriate, relevant, and meaningful consent process. Study results highlight the complexities of decision-making surrounding autopsy, which is guided by a multitude of issues related to belief systems, psychosocial factors, and the actual biological procedures.

Family member respondents typically reported multiple reasons for acceptance and refusal of postmortem procedures, underlining the multifaceted nature of decision-making. Most families who accepted postmortem conveyed uncertainty about the medical diagnosis causing the death. Strikingly, in several instances, the deceased had been hospitalized over a long period, suggesting that the perceived inconsistencies in the clinical diagnoses or lack of information sharing between health providers and caregivers prompted families to seek a causal explanation. Research carried out in the same region of Tanzania reported that physicians often withhold diagnostic and prognostic information because of cultural sensitivities and treatment availability and costs, which may at least in part explain our findings. ${ }^{25}$ Status and power dynamics may also inhibit communication between clinicians and patients, as has been described in other contexts. ${ }^{26}$ Our study results suggest that lack of confirmed diagnosis of in-hospital deaths, which has been previously reported as common in the region ${ }^{12,13}$ and is the basis for ongoing fever research, leads to concerns among family members of decedents and may raise suspicions of supernatural COD.

Notable was the preponderance of witchcraft beliefs associated with the death. An unexpected finding was that postmortem is perceived as a means to determine whether witchcraft had a role in the death. Families accepting postmortem contended that if postmortem failed to identify a biomedical explanation, witchcraft would be confirmed. Interestingly, witchcraft allegations have been reported as a possible reason for acceptance of needle biopsies in other contexts. ${ }^{27}$ Our results illustrate that the nature of deaths attributed to witchcraft by families, frequently viewed as sudden and inexplicable, prompts the desire to learn the cause of death. In several instances, before death, the deceased was reported to have had interactions with someone perceived as untrustworthy, raising suspicions about malicious intent and warranting postmortem. Other evidence shows that negative and unexpected events are the ones for which people are most likely to seek a causal attribution, particularly related to external or supernatural causes. ${ }^{28}$ Social science researchers in Tanzania have reported that spiritual and witchcraft beliefs are commonly invoked to explain inexplicable events and misfortune, particularly in regions of the country where the practice of Christianity and Islam is less prevalent. ${ }^{20,29,30}$ Our research involving people officially affiliated with Christianity and Islam illuminated an amalgam of belief systems encompassing biomedical, mystical powers, and supernatural causes, underscoring the widespread nature of indigenous belief systems. Anthropologists have asserted that witchcraft attribution allows people to make sense of calamities perceived to be random, with allegations often involving an individual in their social networks for whom they harbor resentment or envy. ${ }^{31-33}$ Such spiritual models are most persistent and widespread in contexts like Tanzania where education is low, poverty is common, health systems are poor, and medical diagnoses are frequently not available or confirmed. ${ }^{34,35}$ Our findings contradict assumptions made by biomedical researchers that traditional belief systems in LMICs serve as barriers to postmortem acceptance. ${ }^{2,3}$

Death resulting from chronic illness or a condition presumed to have a clinical diagnosis were reasons to consider postmortem unnecessary. Disfiguring the body proved to be a congruent explanation for refusal by families of decedents. Disfigurement has been reported as a reason for families to decline postmortem in other African countries and is considered a comparative advantage to less invasive MITS procedures. ${ }^{9,27,36}$ Although concerns about misappropriation of organs were commonly referenced, these beliefs were not primary reasons for refusal. Similar apprehensions about selling organs for transplantation and manufacture of medications have been reported in neighboring Uganda and Zambia, signaling their prevalence and raising questions about these concerns. ${ }^{10,11}$ Research has uncovered networks involving commodification of human organs procured from marginalized populations for transplantation. ${ }^{37-39}$ Although we are unaware of international trafficking of human organs from Tanzania for transplant purposes, study respondents did disclose that human organs are sold to 
traditional healers for witchcraft purposes. Many countries in Africa are reported to have an undercover market for body parts and corpses sold to indigenous healers who make promises to create concoctions to heal and enhance personal wealth (B. Koigi, personal communication). In Tanzania, where the body parts of people with albinism are believed to have magical properties that can be used in witchcraft to deliver wealth, power, and good fortune, albino peoples have been targeted for limbs and organs to supply a lucrative black market, leading to the institution of government regulations to stop the practice. ${ }^{40,41}$ We suspect that the highly sensitive topic related to "trade in organs" and the elusive nature of the data influenced respondents to cite organ removal as a secondary reason for refusal.

Information on people's views regarding COD collected during the preliminary, formative phase was expected to be related to actual acceptance and rejection of procedures, which was sometimes, but not always, the case. Several predictions made during the formative phase were refuted by families approached for postmortem, which is not surprising given that the backgrounds of respondents and the circumstances under which they were interviewed were very different. Examples include that God's will or predestination would be a reason for refusal, suspected medical negligence would lead to acceptance, and stigma attached to HIV/AIDS would cause refusals, with family members of HIV-infected decedents primarily declining because they believed the cause of death was already known. Discrepancies between findings collected during the hypothetical, formative phase and family respondents confronted with emotive and actual decisions about postmortem highlight the importance of information gathering with family members of people recently deceased. Initial exploratory data are intended to inform the development of the study and not as conclusive data surrounding willingness to accept autopsy procedures and the associated reasons. Social science research relying on formative studies to examine acceptability of full autopsy and minimally invasive procedures may be limited because of their hypothetical nature.
The timing and way families were approached influenced acceptance and refusal of postmortem examination. Families who accepted were contacted after the initial shock of the death dissipated, allowing for focused interactions with the authorization team. A one-on-one exchange permitted the transfer of information that enhanced an understanding of and perceived value in postmortem procedures, particularly related to the potential medical benefits to the family and community. These characteristics were reported to be a leading reason for acceptance both in this study and in research examining MITS acceptability. ${ }^{27}$ By contrast, many families who elected to decline were approached while grieving or arranging the burial, with over half contacted by telephone. These factors negated the possibility of essential information sharing about the postmortem procedures highlighted during the formative research phase and the possibility of establishing a rapport based on trust. The perception that hospital staff introduced the possibility of postmortem procedures while the patient was living raised doubts about the hospital care and likely served as a deterrent to acceptance. Preconceptions about postmortem, particularly the association with wrongdoing surrounding the death, also provoked anxieties about why families were selected and the purpose of procedures, undermining trust. Research examining acceptability of autopsy procedures has emphasized that timing and forming trust are central to acceptance. ${ }^{36,42}$ Deviations from best practices identified through the formative research during autopsy authorization, a complex interaction between medical teams and family members, highlight the need to audit and monitor the quality of the authorization process for adherence to the recommended guidance, especially in the context of research. Other research has elucidated differences between professional health workers and families regarding the perceived counseling needs of bereaved relatives requested postmortem examination. ${ }^{43}$ Communication during authorization must be informative but also sensitive to emotional and psychosocial issues shown to influence acceptance. ${ }^{43,44}$ Box 2 presents a set of findings based on our work and other studies that should be considered when seeking postmortem approval. ${ }^{27,36,44}$

Box 2

Key findings related to autopsy authorization

- Timing of contact with the family is critical and must:

- Respect the need for families to grieve

- Be carried out in advance of burial preparations

- Authorization must be carried out in person and in a private location

- Families need to be clearly informed about:

- Why they were selected to participate in the study

- Autopsy procedures

- Potential medical benefits

- Communication with families should:

- Use easily understood terminology

- Be sensitive to psychosocial issues

- Take into account preconceptions about postmortem

- Be interactive

- Those seeking authorization need to show sympathy toward the family and be transparent and knowledgeable about the procedures

- Postmortem should never be introduced while the patient is living 
Despite widespread misconceptions about postmortem procedures and deficiencies identified during the authorization process, 117 (29\%) of 407 families approached have accepted postmortem during the ongoing febrile illness study, of which 95 were CDA and 22 MITS. $^{45}$ The proportion of families accepting postmortem procedures is higher than that in Zambia and lower than studies in the United Kingdom and Uganda. ${ }^{10,11,43}$ These acceptance levels are particularly surprising given the limited community engagement activities. We hypothesize that improvements in the authorization approach along with community-based awareness raising aimed to increase knowledge about the benefits, dispel preconceived misconceptions, and alleviate fears would better prepare families and increase the uptake of postmortem examination.

In conclusion, uncertainties about the contribution of specific COD limit the development of effective treatment and health programming of curative and preventive measures in LMICs with high maternal and child mortality and low life expectancy. Findings from our study highlight that family decision-making in these settings regarding autopsy is multifaceted, encompassing a complex configuration of biomedical knowledge, traditional beliefs, and psychosocial factors. Study results explain why postmortem acceptance can be high in contexts such as northern Tanzania where spiritual beliefs, traditional medical practices, and causal explanations for mortality associated with witchcraft practices are widespread, refuting assumptions of low acceptance in resource-poor settings. Maintaining an authorization approach that is sensitive to the psychosocial needs of grieving family members and religious backgrounds and provides families with the knowledge needed to make an informed decision is critical to acceptance. The in-depth approach used during this study elicited details about the complex interrelationships between cultural meanings and knowledge associated with illness and death that quantitative research cannot provide.

Received January 13, 2020. Accepted for publication June 14, 2020.

Published online August 3, 2020.

Acknowledgments: We thank our study team for their efforts in this research: Nathaniel Kalengo, Christopher Swai, Jerome Mlangi, Lilian Ngowi, Flora Mboya, Edna Ngowi, Rither Mhela, Euphrasia Mariki, Tumsifu Tarimo, Stephen Sikumbili, Edward Mshana, Erica Chuwa, and Daniel Mauya. We also thank physicians from both hospitals who are involved in the INDITe parent study: Alex Mremi, Patrick Amsi, Kajiru Kilonzo, Furaha Lyamuya, Grace Kinabo, Ronald Mbwasi, Annette Marandu, and Calvin Mosha. We acknowledge the HubertYeargan Center for Global Health at Duke University and the Duke Global Health Institute for critical infrastructure support for the Kilimanjaro Christian Medical Centre-Duke University Health Research Collaboration. We are grateful to the leadership, clinicians, and patients of KCMC and MRRH for their contributions to this research.

Financial support: This research was supported by the U.S. National Institutes of Health through grant R01Al121378 Investigating Febrile Deaths in Tanzania (INDITe) and K23 Al116869.

Disclaimer: This study was presented in part at the American Society of Tropical Medicine and Hygiene 66th Annual Meeting, Baltimore, MD, November 5-9, 2017, Abstract 230.

Authors' addresses: Lauren S. Blum, Duke University, Durham, NC, E-mail: laurensblum@yahoo.com. Francis P. Karia, Duke University Medical Center, Durham, NC, E-mail: francis.karia@duke.edu. Elizabeth F. Msoka, Kilimanjaro Christian Medical Centre, Moshi, Tanzania, E-mail: e.fbright@kcri.ac.tz. Martha Oshosen Mwanga, The University of Cape Town, Cape Town, South Africa, E-mail: marthaoshoseny@gmail.com. John A. Crump and Matthew P. Rubach, Division of Infectious Diseases and International Health, Duke University Medical Center, Durham, NC, E-mails: john.crump@ duke.edu and matthew.rubach@duke.edu.

\section{REFERENCES}

1. Bassat $Q$ et al., 2013. Development of a post-mortem procedure to reduce the uncertainty regarding causes of death in developing countries. Lancet Glob Heal 1: 125-126.

2. Byass $P, 2016$. Minimally invasive autopsy: a new paradigm for understanding global health? PLoS Med 13: e1002173.

3. Castillo $P$ et al., 2017. Validity of a minimally invasive autopsy for cause of death determination in maternal deaths in Mozambique: an observational study. PLoS Med 14: e1002431.

4. Fligner CL, Murray J, Roberts DJ, 2011. Synergism of verbal autopsy and diagnostic pathology autopsy for improved accuracy of mortality data. Popul Health Metr 9: 25.

5. Menéndez C et al., 2008. An autopsy study of maternal mortality in Mozambique: the contribution of infectious diseases. PLoS Med 5: e44.

6. Turnbull A, Martin J, Osborn M, 2015. The death of autopsy? Lancet 386: 2141.

7. Mohammed M, Kharoshah MA, 2014. Autopsy in Islam and current practice in Arab Muslim countries. J Forensic Leg Med 23: 80-83.

8. Rispler-Chaim V, 1993. The ethics of postmortem examinations in contemporary Islam. J Med Ethics 19: 164-168.

9. Oluwasola OA, Fawole OI, Otegbayo AJ, Ogun GO, Adebamowo CA, Bamigboye AE, 2009. The autopsy knowledge, attitude, and perceptions of doctors and relatives of the deceased. Arch Pathol Lab Med 133: 78-82.

10. Bhat G, Chintu C, Kaluwaji J, Lishimpi K, Lucas S, Maswahu D, 2001. Necropsies in African children: consent dilemmas for parents and guardians. Arch Dis Child 84: 463-467.

11. Cox JA, Lukande RL, Kateregga A, Mayanja-Kizza H, Manabe YC, Colebunders R, 2011. Autopsy acceptance rate and reasons for decline in Mulago Hospital, Kampala, Uganda. Trop Med Int Heal 16: 1015-1018.

12. Crump JA et al., 2013. Etiology of severe non-malaria febrile illness in northern Tanzania: a prospective cohort study. PLOS Negl Trop Dis 7: e2324.

13. Rubach MP, Maro VP, Bartlett JA, Crump JA, 2015. Etiologies of illness among patients meeting integrated management of adolescent and adult illness district clinician manual criteria for severe infections in northern Tanzania: implications for empiric antimicrobial therapy. Am J Trop Med Hyg 92: 454-462.

14. Regional Commissioner's Office, 1998. Kilimanjaro Region Socio-Economic Profile. Dar es Salaam, Tanzania: The United Republic of Tanzania.

15. Hertz J, Madut D, Tesha R, William G, Simmons R, Galson S, Maro V, Crump J, Rubach M, 2019. Self-medication with nonprescribed pharmaceutical agents in an area of low malaria transmission in northern Tanzania: a community-based survey. Trans R Soc Trop Med Hyg 113: 183-188.

16. Leurs R, Tumaini-mungu P, Mvungi A, 2011. Mapping the Development Activities of Faith-Based Organizations in Tanzania. Birmingham, United Kingdom: University of Birmingham.

17. Lodhi A, Westerlund D, 1999. African Islam in Tanzania. Westerlund D, Svanberg I, eds. Islam Outside the Arab World. Richmond, VA: Curzon Press, 97-110.

18. Mukandala R, 2006. Introduction. Mukandala R, Yahiya-Othman S, Mushi S, Ndumbara L, eds. Justice, Rights and Worship: Religion and Politics in Tanzania. Dar es Salaam, Tanzania: E \& D Ltd., 5-17.

19. Howard M, Millard A, 1997. Hunger and Shame: Child Malnutrition and Poverty on Mount Kilimanjaro. New York, NY: Routledge.

20. Lawi $Y$, Masanja $P, 2006$. African traditional religion in Tanzania: essence, practice and the encounter with modernization. Mukandala R, Yahiya-Othman S, Mushi S, Ndumbara L, eds. Justice, Rights and Worship: Religion and Politics in Tanzania. Dar es Salaam, Tanzania: E \& D Ltd., 73-96.

21. Mbiti J, 1990. African Religion and Philosophy. London, United Kingdom: Heineman. 
22. Westerlund D, 1980. Ujamaa Na Dini: A Study of Some Aspects of Society and Religion in Tanzania, 1961-1977. Stockholm, Sweden: Almquist \& Wikseil International.

23. Tjallinks J, van der Wal D, Savage A, 2006. Health beliefs of the urban Pare tribe living in Moshi, Tanzania. Curationis 28: 25-36.

24. ATLAS.ti 7 (computer software) 2013. Berlin, Germany: ATLAS.ti Scientific Software Development $\mathrm{GmbH}$.

25. Harris JJ, Shao J, Sugarman J, 2003. Disclosure of cancer diagnosis and prognosis in Northern Tanzania. Soc Sci Med 56: 905-913.

26. Lupton D, 1994. Toward the development of critical health communication praxis. Health Commun 6: 55-67.

27. Maixenchs $M$ et al., 2016. Willingness to know the cause of death and hypothetical acceptability of the minimally invasive autopsy in six diverse African and Asian settings: a mixed methods socio-behavioural study. PLoS Med 13: e1002172.

28. Fiske ST, Taylor SE, 1991. Social Cognition, 2nd edition. New York, NY: McGraw-Hill.

29. Mesaki S, 1994. Witch-killing in Sukumaland. Abrahams R, ed. Witchcraft in Contemporary Tanzania. Cambridge, United Kingdom: University of Cambridge.

30. Miguel E, 2005. Poverty and witch killing. Rev Econ Stud 72: 1153-1172.

31. Ashforth A, 2001. On living in a world with witches: everyday epistemology and spiritual insecurity in a modern African city (Soweto). Moore H, Sanders T, eds. Magical Interpretations and Material Realities: Modernity, Witchcraft and the Occult in Postcolonial Africa. London, United Kingdom: Routledge, 1-27.

32. Evans-Pritchard E, 1937. Witchcraft, Oracles and Magic Among the Azande. Oxford, United Kingdom: Clarendon Press.

33. Geshiere P, 1997. The Modernity of Witchcraft: Politics and the Occult in Postcolonial Africa. Charlottesville, VA: University of Virginia Press.

34. Lieban R, 1967. Cebuano Sorcery; Malign Magic in the Philippines. Oakland, CA: University of California Press.
35. Spencer P, 1965. The Samburu: A Study of Gerontocracy. London, United Kingdom: Routledge.

36. Gurley ES, Homaira N, Sultana R, Sejvar JJ, Hossain MJ, Parveen S, Islam MS, Luby SP, Nahar N, Rahman M, 2011. Family and community concerns about post-mortem needle biopsies in a Muslim society. BMC Med Ethics 12: 10.

37. Scheper-Hughes N, 2000. The global traffic in human organs. Curr Anthropol 41: 191-224.

38. Scheper-Hughes N, 2001. Bodies for sale-whole or in parts. Body Soc 7: 1-8.

39. Shimazono Y, 2007. The state of the international organ trade: a provisional picture based on integration of available information. Bull World Health Organ 85: 955-962.

40. Dave-Odigie C, 2010. Albino killings in Tanzania: implications for security. Peace Stud J 3: 68-75.

41. Masanja MM, 2015. Albinos' plight: will legal methods be powerful enough to eradicate albinos' scourge? Int J Educ Res 3: 231-244.

42. Banyini AV, Rees D, Gilbert L, 2013. "Even if I were to consent, my family will never agree": exploring autopsy services for posthumous occupational lung disease compensation among mineworkers in South Africa. Glob Health Action 6: 181-192.

43. Heazell AEP, McLaughlin MJ, Schmidt EB, Cox P, Flenady V, Khong TY, Downe S, 2012. A difficult conversation? the views and experiences of parents and professionals on the consent process for perinatal postmortem after stillbirth. BJOG 119: 987-997.

44. Sherwood S, Start RR, 1995. Developing communication skills in medicine asking relatives for permission for a post mortem examination. Postgrad Med J 71: 269-272.

45. Karia FP, Mwanga MO, Msoka EF, Maro VP, Crump JA, Rubach MP, Blum LS. Social acceptability of complete diagnostic autopsy and minimally invasive tissue sampling in the Kilimanjaro Region of northern Tanzania. American Society of Tropical Medicine \& Hygiene 68th Annual Meeting Abstract Book, Abstract 1393. November 20-24, National Harbor, Maryland: American Society of Tropical Medicine \& Hygiene. 